\title{
Trabalho escravo contemporâneo no Brasil na perspectiva da atuação dos movimentos sociais
}

\author{
Graziella Rocha \\ Universidade Federal Fluminense (UFF)
}

\author{
André Brandão \\ Universidade Federal Fluminense (UFF)
}

Trabalho escravo contemporâneo no Brasil na perspectiva da atuação dos movimentos sociais

Resumo: O artigo apresenta um panorama de cinco décadas da luta contra o trabalho escravo contemporâneo no Brasil. Expõe a atuação de movimentos sociais que batalharam para colocar esse tema no cerne dos debates nacionais, de forma que, atualmente, $o$ assunto configura-se como prioritário na agenda de defesa e promoção dos direitos humanos. Indica, através da análise, que as iniciativas públicas e privadas nos últimos anos avançaram bastante, mas devido aos conflitos de interesses peculiares à questão, a erradicação definitiva do trabalho escravo ainda está longe de acontecer. Tem o propósito de contribuir para o conhecimento do contexto em que se desenvolveram as ações contra o trabalho escravo contemporâneo no Brasil e o seu atual momento, destacando os impasses na implementação dos Planos Nacionais e na aprovação da Proposta de Emenda Constitucional (PEC) do Trabalho Escravo.

Palavras-chave: Trabalho escravo contemporâneo. Movimentos sociais. Agenda.

\section{Contemporary Slave Labor in Brazil from the Perspective of Participation in Social Movements}

Abstract: This article presents an overview of five decades of struggle against contemporary slave labor in Brazil. It analyzes the action of social movements that fight to place this issue at the heart of national debate, making it a priority on the human rights agenda. The analysis indicates that recent public and private initiatives have made considerable advances, but due to conflicts of interests particular to the issue, slave labor is still far from being eradicated. The paper contributes to the knowledge of the context in which actions are taken against contemporary slave labor in Brazil and the current situation, highlighting impasses in the implementation of national plans and in the approval of a Proposed Constitutional Amendment (PEC) concerning Slave Labor.

Keywords: Contemporary slave labor. Social movements. Agenda. 


\section{Introdução}

O Brasil tem em sua constituição a ligação íntima com a mácula do trabalho escravo, que se iniciou com a exploração de mão de obra indígena e se consolidou com a exploração de negros africanos e seus descendentes, o que por mais de três séculos configurou suas relações econômicas e sociais. A verdade é que, guardadas as devidas proporções, nunca deixou de existir o trabalho escravo no Brasil. Mesmo após a sua abolição formal, em 1888, a escravidão permaneceu e, ao longo dos anos, adquiriu novos formatos. Esse é um fenômeno que ocorre também em diversos países.

Devido ao interesse em aumentar o lucro à custa do trabalhador, essa prática persistiu ao longo dos anos e manteve-se tão vantajosa quanto à época do Brasil colônia e império. Como indica Figueira (2004, p. 41-42), diferentemente do modelo vigente no Brasil do século 16 ao 19, no qual a prática da escravidão era lícita, a escravidão contemporânea é ilegal, ocorre na marginalidade e, se antes o pretexto para escravizar era a cor da pele, hoje é a pobreza que distingue os "senhores" de seus subordinados. A falta de oportunidades faz com que trabalhadores sejam atraídos por falsas promessas de emprego e melhores condições de vida, que os levam para situações que se assemelham àquelas vividas pelos escravos nos primórdios desta nação.

No passado, o escravo era visto como um bem material, que deveria ser minimamente preservado. Era mais caro comprar um novo escravo do que manter suas condições mínimas de sobrevivência. Hoje, pode se tornar mais simples descartar um trabalhador do que assegurar os seus direitos e as suas condições materiais e, embora o trabalhador não seja mais uma propriedade de seu soberano, ele muitas vezes é considerado como um produto para consumo imediato e posterior descarte.

A situação do Brasil perante a escravidão contemporânea é ainda muito problemática, apesar dos esforços feitos nos últimos anos pelo Governo Federal. Dados disponíveis no relatório de fiscalização do Ministério do Trabalho e Emprego (MTE) (BRASIL, 2012) revelam que, entre 1995, quando iniciaram as ações de fiscalização voltadas ao enfrentamento do trabalho escravo no Brasil, e o segundo semestre de 2012, 39 mil pessoas foram encontradas em situação de trabalho análogo ao de escravo - conforme tipificado no artigo 149 Código Penal Brasileiro em vigor (BRASIL, 1984) - dentre elas, mulheres, crianças, homens, brasileiros e estrangeiros.

O trabalho escravo atinge, principalmente, o trabalhador no meio rural, em diferentes atividades, em especial aquelas ligadas à pecuária, à produção de carvão, à extração do látex e de madeira, à produção de cana de açúcar, dentre outras. Devido à natureza oculta e à dificuldade de acesso às localidades onde ocorre a exploração, é difícil mensurar, com exatidão, quantos trabalhadores estão, neste momento, escravizados. Segundo estimativa da Comissão Pastoral da Terra (CPT), endossada pela Organização Internacional do Trabalho (COSTA, 2010), aproximadamente 25 mil pessoas no Brasil estariam sujeitas a essas condições, ainda que esse número seja de difícil comprovação.

Por meio de revisão bibliográfica, este artigo descreve um panorama da construção da agenda para a erradicação do trabalho escravo no Brasil. A questão é analisada à luz dos conflitos de interesses e da ação de movimentos sociais, os quais há 50 anos lutam para transformá-la em objeto passível da elaboração e implementação de políticas públicas voltadas à sua superação. São descritas quatro fases que se iniciam na década de 1960, quando, atores da sociedade civil passaram a denunciar casos de violações de direitos humanos cometidos contra os trabalhadores rurais. Por fim, chega aos conflitos de interesses que ganharam notoriedade no ano de 2012 com a votação da chamada "PEC1 do Trabalho Escravo".

\section{Primeira fase: a questão é desacreditada}

A permanência do trabalho escravo no Brasil, mesmo após a abolição formal, em 1888, sempre foi evidente e denunciada de diversos modos. Já nas primeiras décadas do século 20, por exemplo, por meio de contos, biografias ou romances, autores, como Euclides da Cunha e Ferreira de Castro, utilizaram a categoria "escravidão" para denunciar um regime social de sujeição da força humana para fins lucrativos, principalmente na região amazônica do Brasil. No entanto, o conjunto da sociedade não reconhecia o caráter verídico e político dessas discussões que eram tratadas como ficção.

Como salientam Figueira e Prado (2008), ainda no século 19 denúncias proferidas pelo escritor suíço Thomas Davatz (1815-1888) repercutiram na Europa e tornaram conhecida a situação de trabalhadores europeus obrigados a trabalhar para pagar as dívidas adquiridas com a viagem até o Brasil. Essas denúncias provocaram uma reação contrária à emigração de europeus para o Brasil e obrigaram o Governo a rever sua política de imigração e a melhorar o sistema de transporte e distribuição de colonos pelo país.

Por muitos anos, o Brasil não reconheceu a permanência sobre seu solo de práticas escravizantes e, por um longo período, a questão do trabalho escravo permaneceu em um "estado de coisas", nos termos postos 
pela cientista social Maria das Graças Rua (2009, p. 5), que despertava a indignação de alguns grupos. Especialmente membros da Igreja Católica e integrantes de movimentos sociais ligados às questões agrárias demonstravam as especificidades e dimensões desse problema, mas não conseguiam fazer com que a situação ganhasse visibilidade suficiente para torná-la objeto de ações públicas, na direção de sua erradicação. De fato, ao longo da história do Brasil, denúncias contra o trabalho escravo somente obtiveram algum êxito quando conseguiram, de alguma forma, ganhar projeção em cenários internacionais.

Os esforços para dar visibilidade a esse tema começam a ganhar relevância na década de 1960, quando atores da sociedade civil passaram a denunciar casos de trabalho escravo no meio rural e a sua relação com o regime autoritário e com o próprio modelo de desenvolvimento que estava sendo gestado no país. Como indicam Miani e Fregonesi (2007), naquele período, o Brasil vivenciava um severo regime de censura e perseguição política, o que obrigava os movimentos sociais a construírem estratégias alternativas de comunicação como forma de resistência.

Esses esforços, algumas vezes, conseguiam extrapolar os limites do território nacional e expor ao mundo a situação conflituosa em que se encontrava o país. Entretanto, as denúncias de ativistas ligados à Igreja Católica foram desacreditadas. Apenas na década seguinte, estes atores conseguiram compor um grupo de pressão ativo, constituindo o universo dos movimentos populares, comprometidos com uma efetiva proposta de transformação das estruturas sociais e econômicas.

\section{Segunda fase: início da ação dos movimentos sociais}

No início dos anos 1970, o Brasil viu a expansão agrícola e o aumento da concentração de terras, desmatamento e atração de trabalhadores para a Amazônia brasileira, o que em pouco tempo mostrou-se fonte de aliciamento ao trabalho escravo. Nesse período, conforme Festa (1986), emergiram movimentos sociais de resistência mais consistentes que os da década anterior, reivindicando espaços e criando polos de confrontação que conseguiam articular diferentes atores sociais como forças de oposição. Dentre esses, destacaram-se entidades ligadas à Igreja, como as Comunidades Eclesiais de Base (CEBs), que desencadearam uma série de movimentos populares não somente ligados aos interesses cristãos, o movimento das mulheres pela educação, o movimento negro e o movimento pela reforma agrária.

Em 1972, a luta contra o trabalho escravo ganhou maior relevo no Brasil quando Dom Pedro Casaldáliga, recém empossado bispo, chegou a São Felix do Araguaia, no Mato Grosso, e fez suas primeiras denúncias sobre as condições desumanas às quais estavam submetidos os trabalhadores da fronteira amazônica. Nessa época, a ditadura militar imperava no Brasil e o problema do trabalho escravo agravava-se e encontrava no Estado o seu principal agente financiador, uma vez que as empresas denunciadas recebiam financiamentos e incentivos fiscais da Superintendência do Desenvolvimento da Amazônia (Sudam).

As denúncias de Casaldáliga eram realizadas, em sua maioria, por meio das Cartas Pastorais e não apenas descreviam as condições degradantes dos trabalhadores como também revelavam suas causas: a concentração de terras e as políticas públicas voltadas para a geração de benefícios para grandes grupos econômicos.

Poucos anos depois, foi fundada a Comissão Pastoral da Terra (CPT), entidade que igualmente foi responsável por divulgar relatos de histórias de cerceamento da liberdade e de sofrimento físico e psicológico a que eram submetidos os trabalhadores rurais do Brasil. Naquela época e ainda hoje, a sede da CPT tem sido local de acolhimento de trabalhadores que conseguiam escapar de fazendas, onde eram submetidos a regimes de trabalho forçado.

Segundo Figueira (2004), as denúncias da CPT eram feitas com base nos depoimentos colhidos desses trabalhadores e, apesar dos horrores apontados, os membros da CPT não eram ouvidos e pouca atenção foi dada às suas denúncias. O problema era tratado como uma questão cultural, como algo natural, não justificando o empreendimento de esforços para modificá-lo. Como relembra Festa (1986), com o passar dos anos, a CPT e outras entidades, como o Conselho Indígena Missionário e a Pastoral Operária, passaram a apoiar a criação de centros de documentação e educação popular em todo o país. Esses centros tiveram papel fundamental na recriação de uma educação popular mais comprometida em aumentar o nível de consciência das classes subalternas. Essa experiência construiu uma significativa produção de folhetos, de cadernos de estudo, materiais para reflexão, cartazes, programas de rádio, que contribuíram para expor os problemas enfrentados por grupos sociais completamente desconsiderados no ordenamento de políticas públicas no Brasil. Exemplo disso foi o lançamento do "Boletim Nacional da CPT", em 1975, que denunciava a grilagem de terra, a ação predatória de grandes projetos agropecuários e, por consequência, a manutenção de um sistema que submetia milhares de trabalhadores à escravidão.

Na década de 1980, o Brasil avançou em seu processo de redemocratização, que atingiu seu ápice em 1988 com a promulgação da chamada Constituição Cidadã. Com o fim da censura, a imprensa brasi- 
leira passou a tratar de temas até aquele momento proibidos, ainda que as abordagens estivessem subordinadas aos interesses editoriais.

Nesse período, as denúncias contra o trabalho escravo passaram a despertar o interesse da grande mídia. Em 1983, por exemplo, em uma pequena reportagem do jornal $O$ Globo, a multinacional Volkswagen foi denunciada pela existência de trabalhadores escravos em uma de suas fazendas, na região amazônica. A notícia teve grande repercussão na imprensa internacional - especialmente em jornais da Alemanha, onde a multinacional é sediada - que passou a solicitar informações mais detalhadas sobre estes acontecimentos. Esse foi o ponto inicial de uma série de ações articuladas entre a sociedade civil (com protagonismo da CPT e dos Sindicatos de Trabalhadores Rurais) e o poder público para a responsabilização daquela empresa pelas condições de trabalho em suas propriedades, no Brasil. Como indica Buclet (2005, p. 5), devido à pressão social, aquela propriedade acabou por ser vendida e a Volkswagen foi obrigada a indenizar três dos trabalhadores que haviam escapado de sua fazenda, no ano de 1983. Apesar disso, iniciativas públicas voltadas ao combate do trabalho escravo somente começaram a serem construídas na década de 1990 e isso se deve a um conjunto de fatores sociais, econômicos e políticos, como veremos a seguir.

\section{Terceira fase: reconhecimento da questão e início das ações de enfrentamento}

Os anos 90 do século 20 foram marcados por períodos de grande recessão econômica e pela crescente luta de parcelas da sociedade civil para a construção de políticas de bem-estar social. É razoável destacar que neste momento ocorrem mudanças na concepção de questão social dentro do próprio aparato estatal brasileiro, até então, marcada pelo caráter punitivo da atuação do Estado. Não se pode afirmar que tais procedimentos estejam de todo superados, dado a atual tendência de criminalização dos movimentos sociais, mas certamente a partir daquele período, o Estado tornou-se mais aberto a incorporar em sua agenda demandas oriundas de parcelas da população que sempre tiveram poucas possibilidades de vocalização.

No que diz respeito ao enfrentamento do trabalho escravo no Brasil, ocorreu a pressão conjunta e articulada de distintos atores sociais, seja de âmbito internacional, promovida pela Organização Internacional do Trabalho (OIT), seja de âmbito nacional, representada por diversos órgãos: Comissão Pastoral da Terra (CPT), Conferência Nacional dos Bispos do Brasil (CNBB), Movimento dos Trabalhadores Rurais Sem Terra (MST) e Ordem dos Advogados do Brasil (OAB). Nesta articulação foram constituídas alianças suficientemente densas para levar denúncias da escravização contemporânea aos organismos internacionais e para forçar o governo a não mais ignorar a questão e a tomar medidas.

O marco dessas denúncias referia-se ao processo, instaurado na Comissão Interamericana de Direitos Humanos, de responsabilização do Brasil por violação dos direitos humanos em relação ao trabalho escravo. Tal processo, que ficou conhecido como "caso José Pereira", levou o Brasil a ser julgado internacionalmente por ter violado a Declaração Universal de Direitos Humanos (1948) e a Convenção Americana de Direitos Humanos (1969) ao não cumprir com sua obrigação de proteger os seus trabalhadores, ao não produzir meios de reparação aos danos sofridos por pessoas submetidas à condição de trabalho escravo e ao não punir aqueles que se beneficiaram desse crime.

O caso do trabalhador José Pereira chegou até a Comissão Interamericana em 1994, por meio da denúncia feita pela Comissão Pastoral da Terra (CPT) e pelo Center for Justice and International Law (CEJIL). Na ocasião, as entidades relataram que o trabalhador, em 1989, havia fugido de uma fazenda localizada no estado do Pará, onde ele e cerca de 60 outros eram obrigados a exercer trabalhos forçados. As autoridades brasileiras nada fizeram para investigar as denúncias e para punir os perpetradores. O processo tramitou por nove anos na Corte Internacional de Justiça até que, em 2003, através de um acordo amistoso, o governo reconheceu a sua responsabilidade em relação ao caso. Indenizou o trabalhador José Pereira e comprometeu-se a desenvolver políticas públicas com a finalidade de erradicar todas as formas contemporâneas de escravidão no país.

Em 1992, o Governo Federal instituiu o Programa de Erradicação do Trabalho Forçado e do Aliciamento de Trabalhadores (Perfor). Entretanto, como comenta Moraes (2007, p. 2), "foi mais uma resposta às denúncias feitas em fóruns internacionais do que uma efetiva vontade política de enfrentar a questão", razão pela qual o programa não obteve efeitos computáveis.

Uma mudança mais significativa nesse quadro só aconteceu em 1995, durante o mandato do presidente Fernando Henrique Cardoso (1995-2003). Em resposta ao crescente aumento no número de denúncias de trabalho escravo, o presidente em uma transmissão de rádio reconheceu o problema e anunciou que tomaria medidas para superá-lo. Foi então que o governo inseriu a questão da escravidão contemporânea em sua agenda e deu os primeiros passos na construção de ações voltadas para a erradicação do trabalho escravo no 
Brasil - essas ações nos governos seguintes conseguiram consolidar a questão como um tema permanente e prioritário para a agenda de defesa e promoção dos direitos humanos.

Naquele momento, o Governo Federal criou o Grupo Executivo de Repressão ao Trabalho Forçado (Gertraf), dentro do Ministério do Trabalho, e o Grupo Especial de Fiscalização (Grupo Móvel) para operacionalizar as ações. O Grupo Móvel - criado e formado por Auditores-Fiscais do Trabalho, Procuradores do Trabalho e, em algumas ocasiões, por agentes das polícias Federal e Rodoviária Federal - até hoje executa operações que, além de resgatar pessoas em situações de trabalho escravo, têm a prerrogativa de atuar no mapeamento de novos focos de exploração e prestar assistência temporária.

\section{Quarta fase: a questão torna-se prioritária na agenda de direitos humanos do Governo}

Em seu primeiro mandato (2003-2006), o presidente Luís Inácio Lula da Silva deu continuidade às ações realizadas pelo governo anterior para a erradicação do trabalho escravo e ampliou os investimentos públicos destinados ao enfrentamento da questão. Em 2003, atendendo às determinações do Plano Nacional de Direitos Humanos, a Secretaria Especial dos Direitos Humanos da Presidência da República lançou o Plano Nacional para a Erradicação do Trabalho Escravo, que apresentou medidas a serem cumpridas pelos diversos órgãos dos Poderes Executivo, Legislativo e Judiciário, pelo Ministério Público e por entidades da sociedade civil brasileira. O documento foi elaborado pela Comissão Especial do Conselho de Defesa dos Direitos da Pessoa Humana (Cddph) e, ainda que não tenha força de lei, foi promulgado como decreto presidencial, expressando o desejo do novo governo em manter o tema no topo de sua agenda.

Entre as diversas propostas do Plano, merecem destaque: a) o apoio do Executivo Federal à aprovação da PEC que prevê o confisco de terras onde forem encontradas pessoas em situação de trabalho análogo ao de escravo; b) a inserção de cláusulas estipulando o impedimento da aquisição e manutenção de crédito rural e de incentivos fiscais para empresas flagradas utilizando o trabalho escravo; c) a disponibilização permanente do Grupo Especial de Fiscalização Móvel; d) a inclusão das ações de combate ao trabalho escravo no Plano Nacional de Segurança Pública e; e) a elaboração de uma política de reinserção social de egressos do trabalho escravo, buscando evitar a reincidência (BRASIL, 2003).

Outra iniciativa do Governo Lula foi a criação do "Cadastro de empregadores que tenham mantido trabalhadores em condições análogas à de escravo", amplamente conhecido como "lista suja" do trabalho escravo (BRASIL, 2004). Nesse cadastro, os nomes dos infratores são incluídos, após decisão administrativa final lavrada em procedimento de fiscalização, e garantidos o contraditório e a ampla defesa dos acusados. De acordo com as regras do Ministério do Trabalho e Emprego (BRASIL, 2011, p. 23), ao final do processo administrativo, criado pelos autos da fiscalização, incluem-se o nome do infrator e o Cadastro Nacional de Pessoa Jurídica (CNPJ) da empresa listada, impedindo assim a concessão de créditos e financiamentos de instituições estatais e agências regionais de desenvolvimento, como o Banco do Brasil, a Caixa Econômica Federal, o Banco Nacional do Desenvolvimento (BNDES) e o Banco do Nordeste.

A criação da "lista suja" foi um instrumento que favoreceu o enfrentamento do trabalho escravo também na perspectiva do desenvolvimento de sanções econômicas aos que se beneficiam desse crime. Por meio desse instrumento, grandes empresas que se beneficiam direta ou indiretamente da escravidão passaram a sofrer pressão de diversos organismos da sociedade civil organizada (nacionais e internacionais). Como esclarece a OIT, em relato de Costa (2010, p. 36), aqueles que entram no cadastro são monitorados durante dois anos consecutivos e os seus nomes somente serão retirados quando atendidas todas as seguintes exigências: a não reincidência; o pagamento de todas as multas resultantes da ação de fiscalização; a quitação dos débitos trabalhistas e previdenciários e a regularização da situação dos trabalhadores.

A primeira avaliação oficial da implementação do Plano Nacional para a Erradicação do Trabalho Escravo foi realizada pela OIT, dois anos após o seu lançamento, por meio de metodologia própria em que foi observado o cumprimento de suas 66 metas. Em seu relatório final, a OIT (SAKAMOTO, 2006, p. 127) apontou, dentre outros aspectos, que o país conseguiu avançar, de modo mais eficiente nas ações de repressão ao crime. Como pontos a serem melhorados no desenvolvimento das ações do Plano, destacou a "falta de vontade política". Para resolver este entrave, recomendou que o Congresso Nacional fosse mais ágil para liberar emendas orçamentárias a fim de suprir as necessidades econômicas das ações de combate ao trabalho escravo e na aprovação de leis que permitissem, dentre outras, a efetivação da reforma agrária. Por fim, foi recomendado que o governo elaborasse um segundo Plano que detalhasse melhor as metas estabelecidas, os atores designados para cumpri-las, os objetivos e os prazos para sua implementação.

Tal sugestão foi acatada pelo o Governo Federal que, em 2008, lançou o $2^{\circ}$ Plano Nacional para a Erradicação do Trabalho Escravo (ainda em vigência), documento que expressa um conjunto de 76 metas 
divididas em ações gerais e específicas, com a descrição da proposta, os órgãos responsáveis pela sua implementação e um prazo para o seu cumprimento.

Dentre os avanços com relação ao primeiro Plano, estão previstos: o forte investimento na criação de medidas para inserir os trabalhadores egressos do trabalho escravo no mercado de trabalho; a criação de mecanismos de apoio ao imigrante ilegalmente explorado no país; a aprovação de mudança no artigo 149 do Código Penal, que aumentaria de dois para quatro anos a pena mínima para quem comete esse crime; o aumento da fiscalização prévia, sem necessidade de denúncia; a priorização da reforma agrária em municípios onde existam trabalhadores escravizados e aliciados; a garantia do acesso prioritário das pessoas resgatadas do trabalho escravo ao Programa Bolsa Família e o compromisso de acelerar a aprovação da Proposta de Emenda Constitucional, conhecida como "PEC 438, do Trabalho Escravo", que propõe o confisco de propriedades onde o trabalho escravo for encontrado (BRASIL, 2008).

Além disso, seguindo diretrizes da descentralização firmadas no pacto federativo, no âmbito subnacional, o II Plano Nacional trouxe um enfoque local à sua proposta, favorecendo, pela proximidade, a operacionalização das ações de combate ao trabalho escravo e o incentivo aos estados e municípios no desenvolvimento de programas que priorizem localidades reconhecidas como redutos de aliciamento de trabalhadores. Nessa perspectiva, a União passou a estimular os governos estaduais e, em menor escala, os municipais a assumirem o papel de articuladores e promotores através das capacitações para a gestão descentralizada e com a oferta de ações voltadas para a qualificação profissional ou para o desenvolvimento regional. A grande estratégia está no estímulo à formação das Comissões Estaduais para a Erradicação do Trabalho Escravo (Coetraes), como instâncias paritárias de participação social, capazes de produzir agendas locais e propagar práticas descentralizadas de planejamento conjunto no enfrentamento desse crime.

Passados os dois mandatos do Presidente Lula, che-

Graças à atuação de sindicatos, de movimentos sociais e dos esforços individuais de militantes, como padres e trabalhadores rurais, a questão do trabalho escravo, vagarosamente, foi deixando um estado de inobservância social e adquirindo relevância

\section{ao ponto de permanecer na} agenda do governo. ga-se ao governo de sua sucessora, Dilma Rousseff. Esta não imprimiu mudanças no esboço da política anteriormente delineada, permitiu a manutenção das ações, em especial aquelas desenvolvidas pelo MTE, porém sem maiores incrementos e com cortes financeiros.

Merece ressalva o compromisso assumido pela própria presidente de priorizar a votação da PEC 438/2001. É uma proposta polêmica porque prevê a alteração do artigo 243 da Constituição Federal, que trata do confisco de propriedades, ampliando a abrangência de expropriações.

A PEC do Trabalho Escravo foi apresentada pela primeira vez em 2001, pelo senador Ademir Andrade (PSB-PA). Porém, somente em 2004, pela pressão da sociedade civil organizada em decorrência do assassinato de dois AuditoresFiscais do Trabalho e de um motorista, no município de Unaí, em Minas Gerais, a matéria entrou na pauta de votação, com alteração no texto inicial. O novo texto ampliou o confisco de propriedades rurais, onde houvesse pessoas em situações de trabalho análogo ao de escravo, incluindo a possibilidade de expropriação condicionada ao uso social de imóveis urbanos, quando utilizados para o exercício dessas atividades. Após a votação em primeiro turno na Câmara, a PEC ficou no ostracismo por oito anos e, somente em 2012, devido ao compro-

misso assumido pelo Executivo Federal, a matéria entrou para votação em segundo turno.

$\mathrm{O}$ processo de votação da PEC trouxe à baila toda a gama de conflitos de interesses que circundam o enfrentamento do trabalho escravo no Brasil. De um lado, representantes de movimentos sociais e organizações da sociedade civil, pela primeira vez, recebem o amplo apoio do Governo Federal e de seus aliados partidários, nesse ponto nevrálgico que é o confisco de terras. Do outro, representantes da bancada ruralista ganham homogeneidade no discurso e passam a colocar em litígio a legalidade do confisco das propriedades e o próprio conceito de "análogo ao trabalho escravo" disposto no Código Penal. Diversos parlamentares passam a defender que não há uma definição clara desse conceito e que a PEC imprime uma "insegurança jurídica" aos grandes produtores rurais e aos empresários do país.

Foram semanas intensas de debates e, após muita pressão da sociedade civil, da bancada do governo e de seus aliados, a matéria entrou em votação na Câmara. Nesse processo de convencimento, é digno de destaque o apoio dado à causa por artistas pertencentes ao Movimento Humanos Direitos (MHuD), 
de intelectuais, centrais sindicais e demais organizações da sociedade civil que fizeram uma verdadeira peregrinação pelos gabinetes dos deputados a fim de convencê-los da importância da aprovação da PEC.

A presença da sociedade civil e de alguns artistas atraiu a atenção da mídia e gerou um clima nacional favorável à votação. O tema tornou-se objeto de disputa política e por três semanas seu conteúdo foi amplamente debatido até que, entrou em votação. Nesse período de tensão na "Casa do Povo", estiveram reunidos militantes de diversas partes do país: representantes de sindicatos, de movimentos rurais, de movimentos feministas, jornalistas e artistas, todos com o intuito de pressionar os deputados a votar a favor da proposta. Nos bastidores, representantes da Frente Parlamentar da Agricultura, conhecidos como a bancada ruralista, articulavam-se para impedir a inserção da PEC na pauta de votações.

Apesar das grandes articulações políticas contrárias à sua aprovação, em 22 de maio de 2012, a Câmara aprovou o texto integral da Proposta, com 308 votos a favor e apenas 29 contrários. Restou ao governo o compromisso pela articulação com o Senado para a formação de uma comissão mista, formada por deputados e senadores, para determinar a regulamentação da emenda constitucional, de modo a produzir uma lei própria para definir os procedimentos de confisco das propriedades.

Em resistência a essa mobilização, alguns deputados da bancada ruralista iniciaram um movimento para que seja redefinido o conceito de "trabalho análogo ao de escravo", adotado no artigo 149 do Código Penal Brasileiro. A alteração do conceito poderá modificar o objeto final da PEC do Trabalho Escravo. De forma sucinta, o que propõem é que sejam considerados casos de trabalho análogo ao de escravo apenas as situações comprovadas de manutenção de trabalhadores em cárcere privado. Outros aspectos que hoje são considerados para a caracterização do crime, como a servidão por dívidas e as jornadas exaustivas de trabalho, por exemplo, ficariam fora dessa conceituação. Alguns parlamentares defendem que existe um exagero na atuação dos Auditores-Fiscais do Trabalho e no ativismo de organizações da sociedade civil que utilizariam a "bandeira" da luta contra o trabalho escravo para denegrir a imagem do agronegócio e ameaçar o direito à propriedade privada.

Para as organizações que há mais de 50 anos lutam para erradicar o trabalho escravo contemporâneo do Brasil, não existe perseguição contra setores específicos da economia brasileira e tampouco a quanto à segurança jurídica às propriedades privadas. O que ainda hoje prevalece são violações de direitos humanos que precisam ser erradicadas.

\section{Considerações finais}

A trajetória do combate ao trabalho escravo no Brasil é marcada pelo lobby de grandes grupos econômicos e pela batalha da sociedade civil que há muitas décadas luta para dar visibilidade ao tema. Graças à atuação de sindicatos, de movimentos sociais e dos esforços individuais de militantes, como padres e trabalhadores rurais, a questão do trabalho escravo, vagarosamente, foi deixando um estado de inobservância social e adquirindo relevância ao ponto de permanecer na agenda do governo. Destacamse os esforços da Comissão Pastoral da Terra (CPT), do MST, do escritório do Brasil da OIT e, o caso mais recente da ONG Repórter Brasil - que tem conseguido manter visibilidade para o tema com a produção de pesquisas e reportagens jornalísticas publicadas, primordialmente, em espaços virtuais, tais como, websites, blogs e redes sociais.

Seria uma falácia o não reconhecimento dos avanços conquistados no enfrentamento do trabalho escravo, nos últimos anos, no Brasil. Como, por exemplo, na repressão ao crime, em decorrência da maior sistematização e um aumento de fiscalizações do trabalho programadas para atingirem áreas com dificuldades geográficas de acesso. Também é digno de destaque o aumento das sanções econômicas e a maior cobrança da sociedade de uma postura socialmente responsável pelas empresas que se beneficiam desse crime. Bancos públicos e privados estão atendendo recomendações para a não concessão de créditos para pessoas jurídicas constantes na famigerada "lista suja", bem como está ocorrendo a intensificação de ações por danos coletivos.

Para que haja superação do problema é preciso perceber o trabalho escravo contemporâneo no Brasil como reflexo de questões sociais graves, tais como a falta de distribuição de terras e riquezas, a precariedade de postos de trabalho e o poderio econômico, político e ideológico de grupos específicos que impedem que mudanças estruturais necessárias para a sua erradicação sejam efetivadas, tais como o aumento da punição e o investimento em alternativas de geração de emprego, renda e acesso a terra.

Afinal, enquanto a impunidade e a falta de oportunidades prevalecerem existirão trabalhadores obrigados a depositarem seus corpos em indignas jornadas e empregadores prontos para explorá-los.

Considerando que aqueles que se beneficiam do trabalho escravo contemporâneo possuem seus interes- 
ses amplamente representados nas esferas da política, há de se ficar atento ao fato de que esse debate estará sempre tensionado entre os grupos que tentam bloquear a construção de medidas eficazes contra a manutenção de ciclos viciosos de exploração e aqueles que lutam para modificá-los.

É importante destacar que, nas batalhas que seguem no Senado pela aprovação da PEC do Trabalho Escravo, se houver outra alteração em sua redação, a matéria deverá ser outra vez submetida aos dois pleitos de votação na Câmara dos Deputados e assim sucessivamente. O que poderá levar mais algumas décadas para a sua conclusão. Enquanto isso não ocorre, apenas medidas paliativas podem ser adotadas e a questão social permanece.

Enfrentar o trabalho escravo ainda é um desafio. O tema está na agenda e os interesses estão sendo disputados. Os avanços e os retrocessos da questão estão diretamente ligados ao modo como a política, ou seja, as interações, a participação social e a distribuição de poder irão se manifestar na arena pública nos próximos anos.

\section{Referências}

BRASIL. Presidência da República. Redação dada pela Lei n. 7.209, de 11.7.1984. Disponível em: <http://www.planalto.gov.br/ ccivil_03/decreto-lei/del2848compilado.htm>. Acesso em: 28 jan. 2013.

. Ministério do Trabalho e Emprego. Plano Nacional Para a Erradicação do Trabalho Escravo. 2003. Disponível em: <http:// www.oit.org.br/sites/all/forced_labour/brasil/iniciativas/plano_nacional.pdf $>$. Acesso em: 10 dez. 2012.

. Ministério do Trabalho e Emprego. Portaria n. 540, de 15 de outubro de 2004. Disponível em: <http://portal.mte.gov.br/ legislacao/2004.htm>. Acesso em: 28 jan. 2013.

. Ministério do Trabalho e Emprego. $2^{\circ}$ Plano Nacional Para a Erradicação do Trabalho Escravo. 2008. Disponível em: <http:// portal.mte.gov.br/data/files/8A7C816A39E4F614013AD5A314335F16/novoplanonacional.pdf>. Acesso em: 12 dez. 2012.

Ministério do Trabalho e Emprego. Manual de combate ao trabalho em condições análogas às de escravo. 2011. Disponível em: <http://portal.mte.gov.br〉. Acesso em: 28 jan. 2012.

. Ministério do Trabalho e Emprego. Relatórios Específicos de Fiscalização para Erradicação do Trabalho Escravo. 2012. Disponível em: <http://portal.mte.gov.br〉. Acesso em: 15 jan. 2013.

BUCLET, B. Entre tecnologia e escravidão: a aventura da Volkswagen na Amazônia. O Social em Questão, Rio de Janeiro: PUC/Rio, n. 13 , p. $5,2005$.

COMISSÃO INTERAMERICANA DE DIREITOS HUMANOS. Relatório de Solução Amistosa n. 95/03. Caso 11.289, José Pereira, Brasil, 2003.

COSTA, P. T. M. Combatendo o trabalho escravo contemporâneo: o exemplo do Brasil. Brasília: OIT, 2010.

FESTA, R. Movimento popular, comunicação alternativa e cultura. In: FESTA, R.; LINS e SILVA, C. E. (Org.). Comunicação popular e alternativa no Brasil. São Paulo: Paulinas, 1986, p. 30.

FIGUEIRA, R. R. Pisando fora da própria sombra: a escravidão por dívida no Brasil contemporâneo. Rio de Janeiro: Civilização Brasileira, 2004.

FIGUEIRA, R. R.; PRADO, A. A. Um velho problema em discussão: o trabalho escravo por dívida. In: SYDOW, E.; MENDONÇA, M. L. (Org.). Direitos humanos no Brasil 2008: relatório da Rede Social de Justiça e Direitos Humanos. São Paulo: Rede Social de Justiça e Direitos Humanos, 2008, v. 1, p. 91-100.

MIANI, R. A.; FREGONESI, L. A. A política de comunicação como fator de organização e mobilização dos movimentos sociais e populares. In: CONGRESSO BRASILEIRO DE CIÊNCIAS DA COMUNICAÇÃO, 30, 2007, Santos. Disponível em: <http:// www.intercom.org.br/papers/nacionais/2007/resumos/R1140-2.pdf>. Acesso em: 12 jan. 2013.

MORAES, M. J. S. Trabalho escravo: da omissão do Estado à Conatrae passando pela bicicleta do Padre Canuto. 2007. Disponível em: <http://www.gptec.cfch.ufrj.br/pdf/trabalhoescravo_genese_out2007.pdf>. Acesso em: 13 jan. 2013.

SAKAMOTO, L. M. (Coord.). Trabalho escravo no Brasil do século XXI. Brasília: OIT, 2006. Relatório técnico.

RUA, M. das G. Análise de políticas públicas: conceitos básicos. 2009. Disponível em: <http://portal.virtual.ufpb.br/biblioteca-virtual/ files/pub_1291087408.pdf>. Acesso em: $20 \mathrm{dez} .2012$.

\section{Nota}

1 Proposta de Emenda Constitucional (PEC). 


\section{Graziella Rocha}

grazielladh@gmail.com

Doutoranda pela Escola de Serviço Social da Universidade Federal Fluminense (UFF)

\section{André Brandão}

aapbuff@globo.com

Doutor em Ciências Sociais pela Universidade Estadual do Rio de Janeiro (UERJ)

Professor da Escola de Serviço Social da UFF

UFF - Programa de Estudos Pós-Graduados em Serviço Social

Rua Professor Marcos Waldemar de Freitas Reis

Bloco E, $3^{\circ}$ andar

Campus do Gragoatá

Niterói - Rio de Janeiro - Brasil

CEP: 24210-201 